\title{
El microcrédito productivo como dinamizador de la economía campesina en la región del Austro
}

Productive microcredit as a catalyst for the peasant economy in the Austro region

Edison Becerra Molina. ${ }^{1} \&$ Gina Cuadrado Sánchez. ${ }^{2}$

\begin{abstract}
.
DOI: https://doi.org/10.33262/visionariodigital.v4i4.1416

The indicators of indigence, inequality in the distribution of income, unemployment and the concentration of credit in the Republic of Ecuador justify the need to focus the study of mechanisms that contribute to economic and social growth.
\end{abstract}

Society creates barriers that deny people access to employability, and therefore access to a better quality of life. The inhabitants of the rural sectors, depending on their geographical location and conditions, have to engage in informal activities such as agriculture mainly for their daily sustenance. Because of its constant informality in underdevelopment; in a world where there are barriers that prevent taking advantage of the markets, accumulating capital and increasing productivity.

The creation of a community bank is part of the solution, playing an inclusive role aimed at providing financial services to this segment of society, with the main premise of contributing to improve the socio-economic conditions of low-income families, in such a way so that small producers can promote agricultural and livestock initiatives that allow improving the quality and diversity of the family diet, integrating families into the economically active population.

The objective of the research was to determine the level of impact and contribution to the real economy of the twenty-four beneficiary sectors of the seed capital placed by the New Horizons Foundation for the granting of microcredits in the Austro region. For this purpose, variables such as: destination of the credit, productive sector it serves, forms of organization, business model focused on training, productivity, credit system, profitability and competitiveness were included in the study.

The analysis carried out in the rural parishes of the Austro region, allowed to identify and measure the impact that microcredit has had in the peasant sectors, through the

\footnotetext{
${ }^{1}$ Universidad Católica de Cuenca, Cuenca, Ecuador, jbecerram@ucacue.edu.ec.
}

${ }^{2}$ Universidad Católica de Cuenca, Cuenca, Ecuador, gcuadrado@ucacue.edu.ec 
empirical verification of the model that was carried out by means of a data panel of twenty-four banks. community communities in the area, additionally, surveys were applied in order to identify the supply of microcredits in the study areas, concluding that the management of the New Horizons Foundation generated a high impact in terms of boosting employment and boosting the economy, achieving the participation and empowerment of families translated into the improvement of productivity and therefore of socioeconomic conditions through access to credit and technical assistance provided by Community Banks, undoubtedly an important factor in the economic development of families in these sectors.

Keywords: Microfinance, organization, social economy, production and marketing.

\section{Resumen.}

Los indicadores de indigencia, desigualdad en la distribución de los ingresos, desempleo y la concentración del crédito en la república del Ecuador justifican la necesidad de focalizar el estudio de mecanismos que contribuyan al crecimiento económico y social.

La sociedad genera barreras que niegan a las personas el acceso a la empleabilidad, y por tanto acceder a una calidad de vida mejor. Los pobladores de los sectores rurales dependiendo de su ubicación geográfica y condiciones, tiene que ocuparse en actividades informales como la agricultura principalmente para su sustento diario. Por su constante informalidad en el subdesarrollo; en un mundo en donde existen barreras que impiden aprovechar las ventajas de los mercados, acumular capital y aumentar su productividad.

La creación de un banco comunitario es parte de la solución fungiendo un papel inclusivo orientado a prestar servicios financieros a este segmento de la sociedad, con la premisa principal de contribuir a mejorar las condiciones socio-económicas de las familias de escasos recursos, , de tal manera que los pequeños productores puedan impulsar iniciativas agrícolas y pecuarias, que permitan mejorar la calidad y diversidad de la dieta familiar, integrando a las familias a la población económicamente activa.

El objetivo de la investigación, fue determinar el nivel de impacto y de contribución a la economía real de los veinte y cuatro sectores beneficiarios del capital semilla colocado por la Fundación Nuevos Horizontes para el otorgamiento de microcréditos en la región del Austro. Para el efecto se incluyó en el estudio variables como: destino del crédito, sector productivo al que atiende, formas de organización, modelo de negocio centrado en la capacitación, productividad, sistema crediticio, rentabilidad y competitividad. 
El análisis realizado a las parroquias rurales de la región del Austro, permitió identificar y medir el impacto que ha tenido el microcrédito en los sectores campesinos, a través de la comprobación empírica del modelo que se realizó mediante un panel de datos de veinte y cuatro bancos comunitarios de la zona, adicionalmente, se aplicó encuestas con el fin de identificar la oferta de microcréditos en las zonas de estudio, concluyendo que la gestión de la Fundación Nuevos Horizontes generó un alto impacto en cuanto al impulso del empleo y la dinamización de la economía, logrando la participación y el empoderamiento de las familias traducidos en la mejora de la productividad y por ende de las condiciones socioeconómicas mediante el acceso al crédito y la asistencia técnica proporcionados por los Bancos Comunales, sin duda, un factor importante en el desarrollo económico de las familias de estos sectores.

Palabras claves: Microfinanzas, organización, economía social, producción y comercialización.

\section{Introducción.}

El microcrédito tiene sus inicios a partir de experiencias como la de Muhammad Yunus, (Premio Nobel de la Paz), quien hace más de 50 años impulsó la dotación de pequeños créditos con propósitos solidarios y de apoyo a los más indigentes, quienes no eran considerados sujetos de crédito por parte del sistema financiero formal. Para conseguir ese objetivo creó como alternativa el Banco Grameen en Bangladesh en el año 1976, que pudiera dotar de recursos económicos a los más pobres y ayudar efectivamente a salir de su situación financiando distintas iniciativas de emprendimiento, estableciendo una metodología crediticia que se sigue hasta la actualidad (Yunus, 2005;Marbán Flores, 2017). Desde entonces, los microcréditos se han convertido en un icono global de la cooperación al desarrollo, hasta tal punto que en 2005 el entonces secretario general de la ONU, Kofi Annan, se refirió a ellos como una herramienta fundamental para la lucha contra la pobreza y la emancipación de las mujeres en todo el planeta.

En la zona del Austro, en la que se centra este estudio se determinó que los individuos que no tienen la posibilidad de producir actividades económicas debido a la carencia de habilidades de las personas o al grado de indigencia en el que viven, han sido atendidos mediante otro tipo de programas sociales, como el bono de desarrollo humano, que surgió como un subsidio para las familias más pobres del país, distribuido en tres grupos: "Bono de desarrollo humano", "Pensión personas con discapacidad" y "Pensión adulto mayor", como 
este bono aparte de ser una ayuda económica para la gran mayoría de familias de escasos recursos, permite a sus beneficiarios participar en programas de desarrollo humano, que buscan "aliviar" la vida de quienes se encuentren en situación de pobreza, pero sin abordar las razones de la desigualdad.

Las micro finanzas en Ecuador han tenido una evolución dinámica en los últimos veinte años, los programas de microcrédito tienen como población objetiva a la gente de escasos recursos que no tiene acceso a los préstamos que otorga la banca comercial, las cooperativas de ahorros y crédito o de otras instituciones públicas, pero a pesar de ello, estas personas tienen la capacidad de emprender actividades que eventualmente aumentarán su ingreso y conllevará una mejora en su calidad de vida, pudiendo cubrir necesidades que anteriormente no se encontraban satisfechas.

Dentro de la presente investigación se determinó que los Bancos Comunitarios contribuyeron a mejorar las condiciones socioeconómicas de las familias de escasos recursos y en especial de las que viven en extrema pobreza. Por consiguiente, se establece que el microcrédito permitió elevar el nivel de subsistencia de las familias de escasos recursos económicos, promoviendo actividades productivas.

La organización, formación y consolidación de los Bancos Comunitarios, tiene como finalidad que los productores se integren en forma paulatina como miembros del Banco Comunal con el propósito de que se vayan involucrando no solo en la transferencia tecnológica, si no en la gestión de todos los procesos de administración, negociación, planificación de la producción y comercialización de los productos cultivados y de los insumos agropecuarios y otras actividades.

No obstante, el afán es integrar a estas familias a la población económicamente activa, en el mismo sentido apoyar al desarrollo intelectual de los socios y socias, con un enfoque económico y social.

De la misma manera se incentivó al desarrollo humano y la práctica de valores como la solidaridad y la cooperación, para mantener la integración y estabilidad entre las familias, los socios, socias y la comunidad rural, además de conservar valores como el valor de la palabra. 
Por su parte, es importante destacar que las mujeres cumplen un rol protagónico dentro de los programas de microcrédito, esto debido a que han demostrado mejores cualidades empresariales y de pago que las registradas por los hombres (Bezboruah \& Pillai, 2015).

En cuanto a los Bancos comunitarios, son organizaciones locales constituidas de hecho, de forma permanente, solidaria y autogestionaria, conformadas por un grupo de aproximadamente desde 15 a 40 socios y socias, microempresarios de escasos recursos económicos, usualmente mujeres y madres de familia que se apoyan mutuamente.

\section{Metodologia.}

En torno a este talante se detalla cómo se sistematiza el trayecto metodológico que se utilizó para llevar a cabo el estudio, la ruta metodológica parte del paradigma de investigación positivista, utilizando un diseño de campo no experimental y transeccional o transversal con apoyo documental, el nivel de investigación fue la investigación descriptiva, Hurtado (2010), quien explica que su propósito es:

Exponer el evento estudiado, haciendo una enumeración detallada de sus características, de modo tal que en los resultados se pueden obtener dos niveles de análisis, dependiendo del fenómeno y del propósito del investigador: un nivel más elemental, en el cual se logra una clasificación de la información en función de las características comunes, y un nivel más sofisticado en el cual se ponen en relación los elementos observados (p. 73).

La población estuvo estructurada por 24 sectores escogidos, correspondiendo a 600 socias mujeres, 94 socios hombres y 28 ahorristas, perteneciendo al universo de la población de 722 beneficiarios, mediante muestreo estratificado se determinó la muestra $\mathrm{n}=192$, considerando la varianza muestral del 0.05, el nivel de confianza representó el 95\% de confianza, el error de la muestra el 1,4\% como aceptable, considerando el tamaño de la población y varianza poblacional, la validez del instrumento fue realizado mediante el juicio de tres (3) expertos con experiencia en el área de micro créditos y metodología.

Con respecto a las técnicas e instrumentos de recolección de datos, de acuerdo con Hernández, Fernández, Baptista (2014), "Implica elaborar un plan detallado de procedimientos que nos conduzcan a reunir datos con un propósito específico" (p.198). Lo 
que ha de suponer entonces, uno de los ejes principales de la investigación, en consecuencia mediante la técnica de la encuesta, se elaboró el instrumento del cuestionario, para validar el microcrédito productivo como dinamizador de la economía campesina en el Ecuador, el mismo tomó en cuenta los criterios de factibilidad (cinco dimensiones), de precisión (5 dimensiones), de utilidad (4 dimensiones), de ética (3 dimensiones), de pertinencia (4 dimensiones), y contenido (4 dimensiones), cada uno de ellos con un conjunto de dimensiones en estricta vinculación con los objetivos de investigación, con opciones de respuesta dicotómicas y observaciones abiertas que a juicio de los validadores fuesen importante para la investigación.

Así mismo, Bernal (2006), afirma que la confiabilidad es la consistencia que tiene el instrumento y que permite evaluar, mediante una prueba piloto, verificando así su veracidad. Es por ello, que la confiabilidad se aplicó el coeficiente de Alfa de Cronbach, el cual es empleado cuando el instrumento comprende ítems con alternativas de respuestas múltiples.

De igual forma, para determinar la confiabilidad del cuestionario elaborado, se procedió aplicar una prueba piloto a 30 beneficiarias, que no forman parte de la muestra y que corresponden a la comunidad Rosario de Mojas de la Parroquia Guapán del cantón Azogues, todos ellos con características similares a los sujetos de este estudio, administrando una escala, de 12 ítems, a una muestra de $\mathrm{n}=20$. De acuerdo con los resultados anteriores, se concluyó que la escala tiene una confiabilidad de consistencia interna muy alta, suficientemente alta como para ser considerada fiable. En conclusión, la confiabilidad del instrumento fue de 0,9 muy alta, así mismo, fue importante la utilización de la herramienta estadística para el desarrollo de la investigación, recurriéndose a la estadística descriptiva, lo que permitió la recolección, organización y presentación de datos, con el apoyo de tablas y figuras, los resultados obtenidos de la aplicación de los cuestionarios en relación con los objetivos planteados del presente estudio, fueron realizados mediante el software libre SPSS, versión 26.

De igual forma, el procesamiento y análisis de los datos obtenidos a lo largo del proceso de investigación, se realizó, considerando el uso de la triangulación, validez y confiabilidad de los instrumentos. 


\section{Fundamentación Teórica.}

Los microcréditos constituyen, la parte vital de los sistemas financieros de América Latina y el Caribe. La notable expansión del microcrédito demuestra su vialidad y capacidad de contribuir significativamente al desarrollo, mediante las cooperativas de ahorro y crédito y las instituciones financieras que proporcionan una amplia gama de servicios tanto financieros como no financieros a hogares y negocios, tal y como afirma el (Fondo Multilateral de Inversiones FOMIN, miembros del grupo BID. 2011).

Por su parte, el Art. 283 de la Constitución de la República del Ecuador (2008) establece que el sistema económico es social y solidario; reconoce al ser humano como sujeto y fin; propende a una relación dinámica y equilibrada entre sociedad, Estado y mercado, en armonía con la naturaleza; y tiene por objetivo garantizar la producción y reproducción de las condiciones materiales e inmateriales que posibiliten el buen vivir. El sistema económico se integrará por las formas de organización económica pública, privada, mixta, popular y solidaria, y las demás que la Constitución determine. La economía popular y solidaria se regulará de acuerdo con la ley e incluirá a los sectores cooperativistas, asociativos y comunitarios.

Ante lo expuesto, los microcréditos constituyen un fortalecimiento a los procesos productivos de pequeños productores de las provincias del Azuay y Cañar, de la región del Austro, en un trabajo constante, por reducir la pobreza, ofreciendo una alternativa que genera ingresos en base a su propio esfuerzo. El microcrédito consiste en el otorgamiento de un préstamo de monto inferior a los que proverbialmente se concede en la banca pública y privada, cuya finalidad es que el prestatario cuente con recursos financieros para el impulso de una acción provechosa determinada.

Según, Jordán, \& Román (2004), sostienen que el microcrédito es una herramienta financiera que se sustenta sobre la idea sencilla pero poderosa: "Conceder pequeños préstamos a los pobres"; es decir, a personas excluidas de los canales o sistemas financieros tradicionales. Las experiencias de microcrédito demuestran no solamente que los pobres pueden ser sujetos financieramente confiables, sino que, dándoles acceso al crédito, o democratizándolo, se 
obtienen buenos resultados desde un punto de vista bancario; permitiendo al mismo tiempo, una mejora generalizada de su calidad de vida.

Así mismo, Torres (2000), sustenta que la microempresa es la organización económica, administrada por una o más personas emprendedoras, que tienen objetivos económicos, sociales y éticos. Aplica la autogestión y tiene gran capacidad de adaptare al medio.

Por otra parte, Yunus (2006), manifiesta a que la palabra "Microcrédito" no existía antes de la década de 1970. Hoy por hoy, sin embargo, se ha convertido en una demarcación de moda entre los especialistas y los profesionales del desarrollo. Mientras tanto, a ese vocablo se le han arrogado toda suerte de significados. Hoy en día, al referirse a los créditos agrícolas en general, considerados como créditos rurales, así como los créditos cooperativos, créditos de consumo, los créditos de las cooperativas de ahorro y crédito, o a los de los prestamistas, nadie se asombra al asegurar que el microcrédito es una herramienta con muchos años de historia.

Es por ello que, Yunus, mencionado por Calderón (2011), sugiere una clasificación más amplia de microcréditos, para evitar un exceso de malentendidos y de confusión a la hora de hablar sobre el microcrédito, por consiguiente, numera los siguientes:

a) El microcrédito informal tradicional, como pueden ser el crédito de los prestamistas, las casas de empeño, los préstamos de los amigos y los parientes, los créditos al consumo en el mercado informal, entre otros.

b) El microcrédito basado en grupos informales tradicionales.

c) El microcrédito destinado a un tipo de actividad determinada y contratado a través de bancos convencionales o especializados, tales como el crédito agrícola, el ganadero, el pesquero, el textil, entre otros.

d) El crédito rural realizado a través de bancos especializados.

e) El microcrédito cooperativo, tales como bancos comunitarios, cooperativas de ahorro y crédito, sociedades de ahorro y préstamo, cajas de ahorro.

f) El microcrédito para el consumo. 
g) El microcrédito basado en acuerdos de colaboración entre Bancos y las ONG., que son organizaciones independientes y sin ánimo de lucro que surgen a raíz de iniciativas civiles y populares y que por lo general están vinculadas a proyectos sociales, culturales, de desarrollo $\mathrm{u}$ otros que generen cambios estructurales en determinados espacios, comunidades, regiones o países.

h) El microcrédito de Grameen.

i) Otros tipos de microcréditos no gestionados por ninguna $\mathrm{ONG}$ pero que tampoco requieren garantía o aval.

Es por ello que, esta clasificación, pretende ordenar diversos tipos de microcrédito con un determinado propósito: de recibir y pagar préstamos para financiar alguna actividad productiva y rentable, nueva o existente, promover el hábito del ahorro familiar a fin de ayudar, para realizar inversiones o cubrir gastos extraordinarios, promover la ayuda mutua y el "empoderamiento" de los socios y socias mediante charlas, dinámicas, y motivaciones varias; y, ganar confianza en sí mismos y lograr el respeto de sus familiares y vecinos.

Otro aspecto importante son los principios generales de los Bancos Comunitarios entre los que se destaca la auto sostenibilidad para generar beneficios comunes, no en busca del enriquecimiento personal, sino en la obtención de un logro social, importante también será el libre acceso y retiro voluntario, así como el control democrático y el retorno de excedente.

Los Bancos Comunitarios nacen con la finalidad de contribuir a mejorar las condiciones socio económicas, al generar mayores ingresos que tenderán a brindar acceso a una mejor nutrición, salud, educación y bienestar para sus hijos, en tal sentido fue importante dentro de la investigación tener presente los recursos humanos, que implica, personas trabajadoras, entusiastas y comprometidas con el adelanto de su comunidad, ansiosas por emprender y aprender, otro aspecto que se debe tener en cuenta son los profesionales que transmitieron sus conocimientos teóricos y prácticos y constituyeron sus guías en las etapas iniciales que impulsa la Fundación Nuevos Horizontes.

En lo que respecta, a los recursos económicos tenemos el ahorro, el aporte propio de los socios y socias, conocida como contraparte, además de otras organizaciones, que podríamos 
catalogarlo como capital semilla, dentro de la presente investigación se determinó recursos administrados para su entrega por la Fundación Nuevos Horizontes.

\section{Resultados.}

Los resultados, constituyen hallazgos derivados del presente estudio, en correspondencia con los objetivos de desarrollo de los microcréditos, con el objeto de contribuir a mejorar las condiciones de vida y reducir los niveles los niveles de pobreza de la población objeto de estudio.

La tabulación e interpretación de los cuestionarios dirigidos a los beneficiarios de los microcréditos impulsados por la Fundación Nuevos Horizontes, fueron en un total de 12 ítems, para el presente análisis se han seleccionado únicamente seis, los más transcendentales.

\section{Indique el cantón al que corresponde su Banco Comunitario.}

Figura 1. Cantones al que corresponde los Bancos Comunitarios.

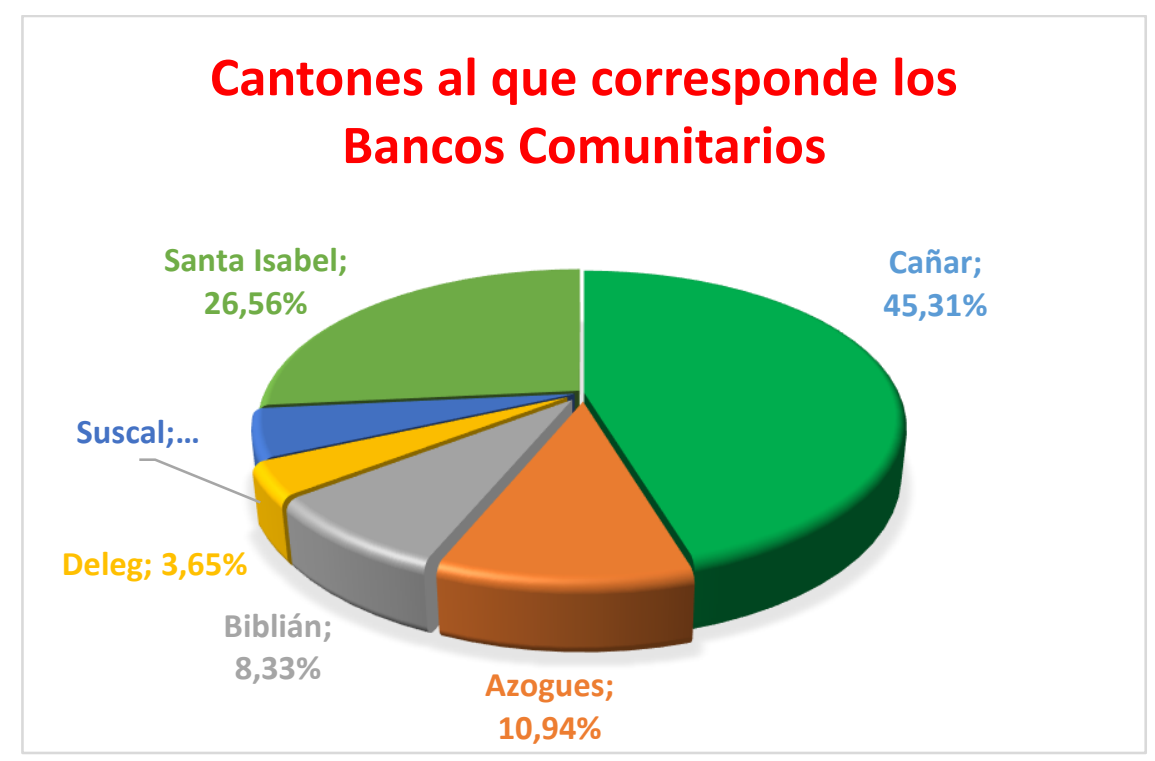

Fuente: Elaboración propia (2020).

El análisis de la figura $\mathrm{N}^{\circ} 1$, con respecto a los cantones en los que están instaurados los Bancos Comunitarios, se encuentran en las provincias de Cañar y Azuay, con respecto a la 
provincia del Azuay le corresponde el cantón de Santa Isabel con el 26.56\%, en tanto que, en la provincia del Cañar, existen mayoritariamente Bancos Comunales en el siguiente orden: Cañar con el 45,31\%, Azogues el 10,94\%, Biblián el 8,33\%, Suscal el 5,21\%; y Deleg el $3,65 \%$, acumulando en la provincia del Cañar el 73,44\%, en tanto que en el Azuay se concentrael 26,56\%, ocasionado un alto impacto al beneficiar en su totalidad a sectores rurales, sobre el bienestar de las familias asociadas, de allí que el microcrédito no solo se traduce en el progreso de la situación económica, sino que mejora su posición en la familia y en la sociedad, alcanzando una alta autoestima, además que los microcréditos tienen un efecto multiplicador muy importante, en mejorar la calidad de vida de las individuos.

Señale las siguientes opciones con respecto a los recursos otorgados en calidad de préstamos, a que actividad fueron destinados.

Figura 2. Actividades en las que fueron destinados los préstamos

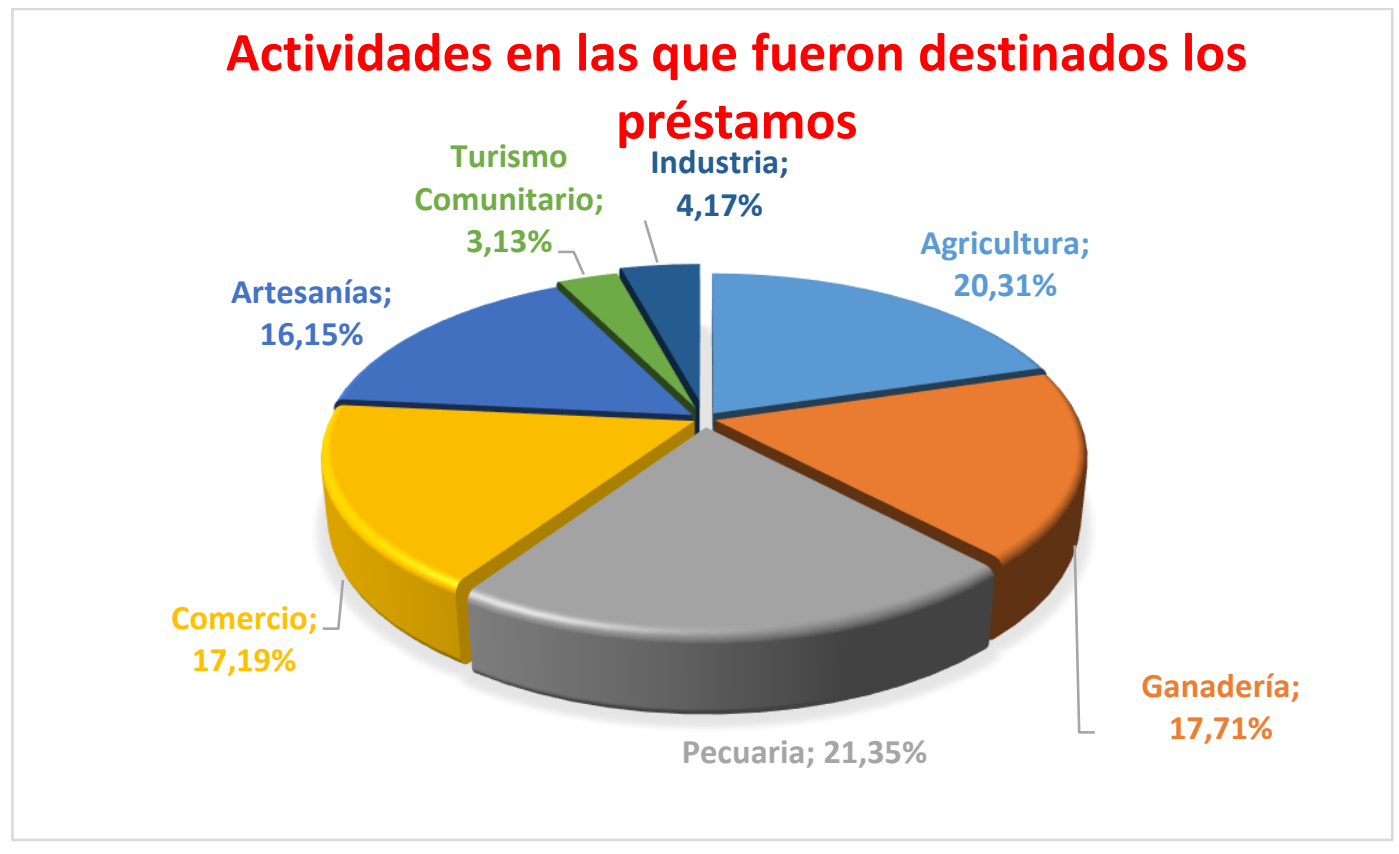

Fuente: Elaboración propia (2020).

Con respecto a que actividad fueron destinados los recursos otorgados en calidad de préstamos, de las encuestas dirigidas a los beneficiarios de los Bancos Comunitarios, manifestaron que en un 20,31\% invirtieron a la agricultura, el $21,35 \%$ en producción 
pecuaria, el 17,71\% en ganadería, el 17,19\% en comercio, el 16,15\% en artesanías, el 4,17\% en Industria y el 3,13\% en turismo comunitario, de allí que la estrategia que han utilizado los usuarios de los Bancos Comunitarios, ha sido impulsar y sostener el crecimiento económico, mediante estas actividades productivas.

Todos aquellos negocios que dependiendo de la zona e iniciativa que sus habitantes, se puedan desarrollar, de acuerdo al análisis, señalando que bajo ningún caso se financian actividades especulativas ilícitas o reñidas con los principios morales y las buenas costumbres. La información recogida permitió determinar, que los préstamos otorgados por los Bancos Comunitarios, son exclusivamente para financiar actividades económicas productivas existentes o para nuevos micro proyectos de sus miembros.

Señale específicamente en que emprendimiento usted empleo su préstamo otorgado por el Banco Comunitario.

Figura 3. En qué emprendimiento usted empleó su préstamo otorgado por el Banco Comunitario

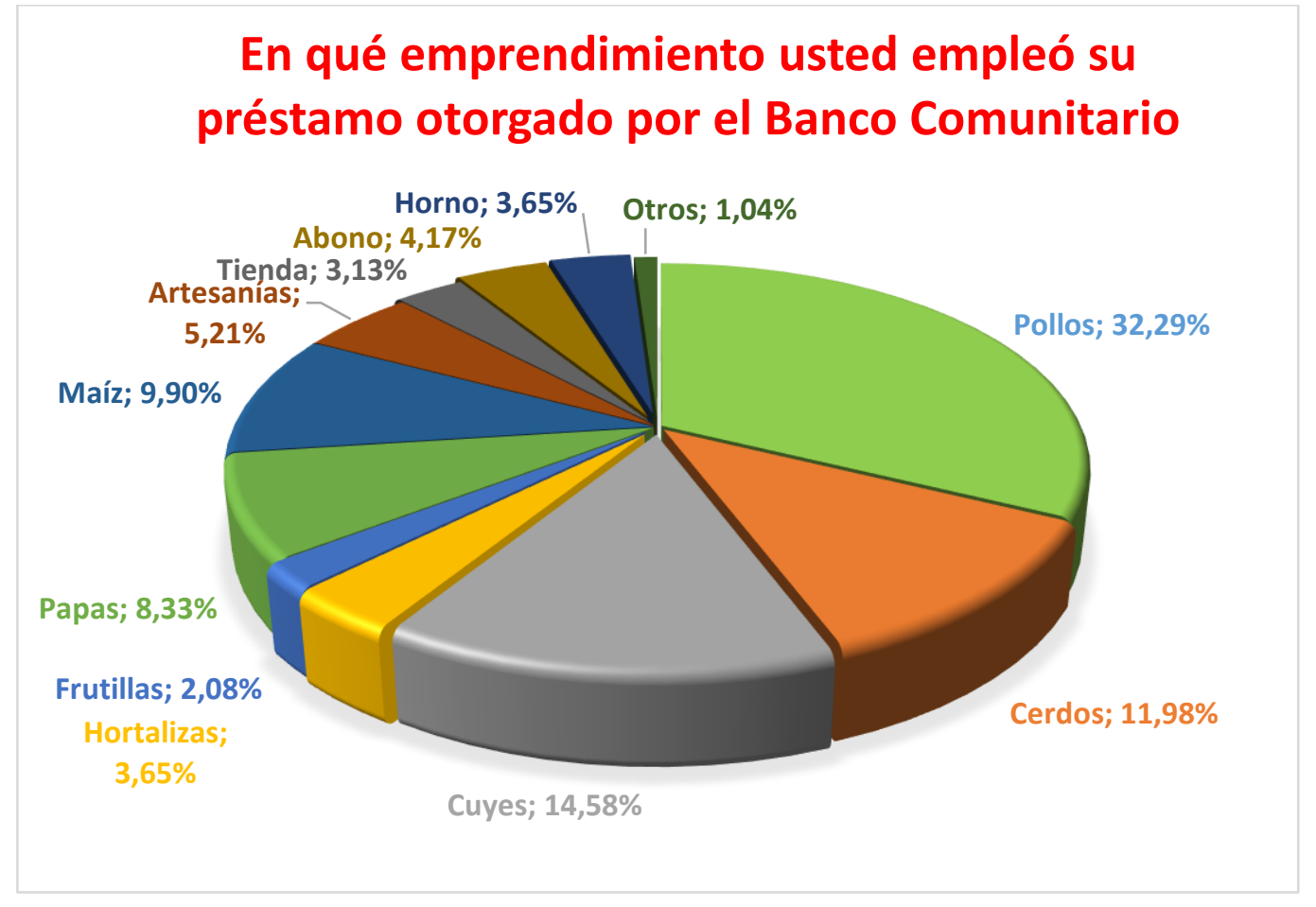

Fuente: Elaboración propia (2020). 
En forma mayoritaria el criterio de los socios de los Bancos Comunitarios encuestados fue que emplearon su préstamo otorgado por el Banco Comunitario para actividades de crianza de pollos en un 32,29\%, el ave más común, para engorde, para vender la carne o los huevos. Es una idea de negocio que requiere mucho trabajo, tiempo y compromiso para obtener ganancias. El objetivo es que el pequeño emprendimiento sea sostenible, de allí que es importante el acompañamiento técnico, para poder aprender todo acerca de la crianza de pollos y sobre su mercado.

En cuanto al emprendimiento de cuyes con el 14,58\%, por ello que la producción de animales menores cobra cada vez mayor interés en nuestra región, como una actividad complementaria dentro del manejo integrado de sistemas de producción de pequeños productores. Esta producción es importante en la economía y estrategia del campesino que le permite el aprovechamiento óptimo de sus recursos, a la vez, elevar el nivel de proteína de origen animal en el área rural, aspectos como el fácil manejo y alimentación son factores que contribuyen al desarrollo de esta actividad.

Por otra parte la actividad de crianza de cerdos, con el 11,98\%, es una de la principales actividades del sector pecuario que llevan adelante los asociados a los Bancos Comunitarios objeto de estudio, los encuestados sostienen que para la producción de cerdos fue importante la capacitación recibida por la Fundación Nuevos Horizontes, los beneficios que han alcanzado son: conocimientos, habilidades y destrezas, que les permitirá organizarse para solucionar posibles problemas y lograr eficiencia y rentabilidad en los micro proyectos porcícolas que establezcan.

Así mismo, con el 9,90\% está la actividad del maíz, esta gramínea que por sus propiedades es consumida en gran parte de la región del Austro, la producción del grano es el maíz blanco, por la asistencia técnica que reciben los productores tienen la capacidad de ofrecer un grano con valor agregado por su alta calidad nutricional, elaborado bajo prácticas agrícolas sostenibles de alta productividad que optimizan el uso de los insumos y reducen el impacto de la actividad agrícola en el medio ambiente, además de generar ingresos para cubrir sus cuotas mensuales por el préstamo y su supervivencia y la de su familia. 
De igual forma, con el 8,33\%, está la siembra de las papas, que es un tubérculo comestible nativo de la región del austro, la papa es un alimento básico a nivel local, regional, nacional e internacional, la patata es un alimento multifuncional, es versátil en todas sus formas y preparaciones, por ello que es un tubérculo altamente energético, posee excelentes propiedades nutritivas gracias a su contenido de vitaminas, minerales y compuestos orgánicos esenciales, además que sirven para el autoconsumo y que ha permitido generar ingresos económicos.

Las demás actividades productivas con mayor porcentaje son registrado son: las artesanías con el 5,21\%, abono el 4,17\%, horno el 3,65\%, hortalizas el 3,65\%, tienda con el 3,13\%, frutillas el 2,08\%, otros por el orden del 1,04\%, en este sentido se puede manifestar que los microempresarios por un lado son los encargados de la fabricación de los productos para el consumidor o en beneficio para la humanidad, como pueden ser alimentos, comercialización de productos de primera necesidad y demás servicios, productos básicos, entre otros, de allí que se le menciona a una actividad productiva a todo aquellos que ayuda al ser humano a lograr cierto desarrollo físico y espiritual, a lograr beneficios para mejorar la calidad de vida.

\section{Usted que transacción ha realizado dentro del Banco Comunitario.}

Figura 4. Transacciones que ha realizado en el Banco Comunitario

\section{Transacciones que ha realizado en el Banco Comunitario}

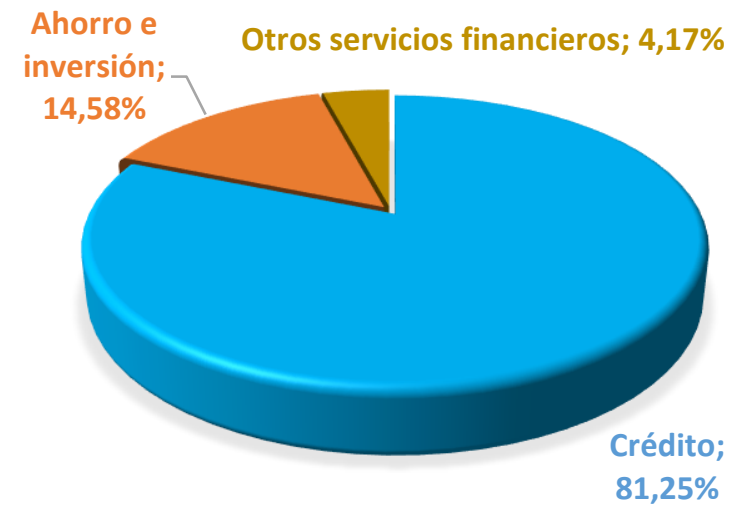

Fuente: Elaboración propia (2020). 
En lo que respecta a las transacciones que han realizado los encuestados en el Banco Comunitario, encontramos con el $81,25 \%$ han realizado créditos, aprobados por los Bancos Comunales, establecido dentro de la política anual de crédito aprobada por la Junta Directiva, destinados para las actividades productivas descritas en la figura 3.

De las investigaciones realizadas sobre los montos, según la política anual de crédito aprobada por la Junta Directiva se establecen los límites mínimos y máximos de los créditos, el monto aprobado de crédito estará sujeto a las necesidades de sus socios y socias, así como a la cantidad de dinero disponible para ser distribuido al mayor número de beneficiarios posibles. Por su parte la tasa de interés es fijada en el "Reglamento interno" del Banco Comunitario, que constituye parte fundamental de la Política Anual de Crédito.

De la mima manera con el 14,58\% está el servicio de ahorro e inversión, de los encuestados 28 personas tienen sus ahorros en el Banco Comunitario, de allí que el ahorro constituye la reserva de dinero que cada socio/a pueda acumular en su cuenta del Banco Comunitario, puede incrementarse con los intereses fijados conforme a la decisión aprobada en asamblea general y regida en el reglamento interno.

El ahorro puede ser empleado en las necesidades emergentes de cada socio, que se presenten con el paso del tiempo. Los ahorros permiten que el cliente tenga una ganancia por el dinero. Así mismo de la información recogida se estableció que existen otros servicios como: las Inversiones a Plazo, que son estrategias que también ofrecen los Bancos Comunitarios para incentivar el ahorro.

De igual forma con el 4,17\% están otros servicios financieros, al respecto los diversos servicios financieros que puede otorgar un Banco Comunitario deben estar elaborados en cada comunidad con el objetivo de establecer soluciones a las problemáticas sociales mediante el aprovechamiento de las potencialidades del territorio para lo cual es necesario conocer la realidad, identificar las necesidades comunitarias, conocer como es el mercado y la competencia.

En tal sentido, el mercado es el lugar donde se reúnen compradores y vendedores con la finalidad de realizar negocios, estableciendo condiciones de: precio, calidad, cantidad, 
plazos, entre otros, por consiguiente, es en la comunidad en donde se configura la oferta y demanda.

Por otro lado, la competencia, representan las personas, grupos de personas, instituciones y organizaciones que ofrecen productos o servicios similares a aquellos que proporcionan las comunidades objeto de estudio, o aquellos que puede ofrecer productos sustitutos.

\section{¿Cuáles de los siguientes enunciados, según su criterio, han impacto los microcréditos?}

Figura 5. Impacto de los microcréditos

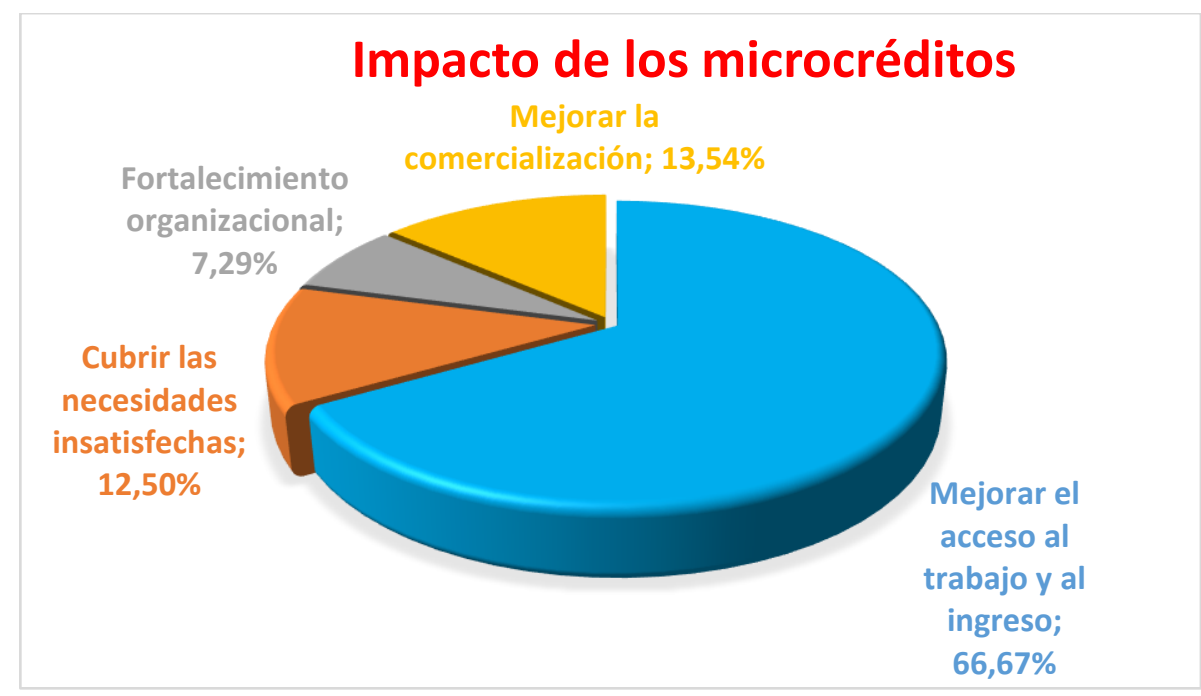

Fuente: Elaboración propia (2020).

Es importante también destacar el impacto que han tenido los microcréditos en los 24 Bancos Comunitarios, los encuestados sostuvieron en un $66,67 \%$ mejoran el acceso al trabajo y el ingreso, en tal sentido, se sostiene que el microcrédito es un tipo de préstamo de pequeña cuantía y corta duración que se concede habitualmente a socios de un Banco Comunitario, con un bajo nivel de recursos, no tienen avales y, por tanto, son aislados de la banca tradicional. Los microcréditos están dirigidos a personas que no pueden solicitar un crédito por los sistemas tradicionales, como serían los bancos o cooperativas de ahorro y crédito, por no cumplir con los requisitos que se exigen. Radican en préstamos de una cuantía exigua y de corta duración enfocados a impulsar a esos emprendedores, que teniendo un proyecto empresarial carecen del capital necesario, y requieren instituir su negocio. No obstante, dicho 
crédito permite mejorar de manera significativa sus ingresos por un lado y por otro solucionar pequeños imprevistos de las economías familiares.

Igualmente, con el 13,54\% mejorar la comercialización, los encuestados sostuvieron que los créditos y el acompañamiento técnico proporcionado por la Fundación Nuevos Horizontes, permitió perfeccionar la comercialización de los productos o servicios, lo expuesto, se centra en la acción de comercializar, que consiste en poner a la venta un producto, darle las condiciones comerciales necesarias para su venta y dotarla de las vías de distribución que permitan que llegue al consumidor final.

En lo que respecta, a cubrir las necesidades insatisfechas, los encuestados en un 12,50\% manifestaron que el nivel de necesidades insatisfechas viene dada en base a que algunas personas desarrollan algún tipo de actividad laboral, aquellos consultados indican que reciben remuneraciones por debajo del salario mínimo vital unificado que en el presente año 2020 es de $\$ 400,00$, debido a que trabajan en el sector informal, de allí que la capacidad de ahorro es restringida, debido a sus gastos, dando lugar por tanto a necesidades insatisfechas. Si analizamos el nivel de necesidades insatisfechas antes y después de la obtención del microcrédito, después de poner en marcha su emprendimiento, se evidenció que existe una recuperación importante en el consumo de los asociados al Banco, ya que pueden satisfacer más necesidades que antes que se encontraban insatisfechas, por consiguiente, permitió mejorar el nivel de vida y de sus familias.

Según las encuestas el 7,29\%, sostienen que el crédito fue un factor fundamental para el fortalecimiento organizacional, por tanto, la organización permite al grupo utilizar en mejor forma el esfuerzo y los recursos colectivos, ya sean humanos, materiales y económicos, para lograr los objetivos que se han propuesto. La organización facilita mayor oportunidad para conocer, negociar, demandar y gestionar con gobiernos locales, provinciales y nacionales. Dentro del campo objeto del análisis, se determinó que los Bancos Comunitarios, están constituidos por lo general por mujeres adultas, madres de familia de escasos recursos y residentes estables de una misma comunidad o barrio. Los Bancos pueden aceptar también miembros masculinos, cabezas de familia, solteros, que participen como asociados y ocupando al igual cargos administrativos, todos ellos tienen prospectivas de lograr metas u 
objetivos con el apoyo de las propias personas, o con apoyo de otros sectores con características similares. Son entidades sociales que permiten la asociación de personas que interactúan entre sí para contribuir mediante sus experiencias y relaciones al logro de objetivos y metas determinadas en busca del bienestar común.

\section{Para el desarrollo de su gestión micro empresarial, es importante la dotación de microcréditos.}

Figura 6. Importancia de la dotación de microcréditos.

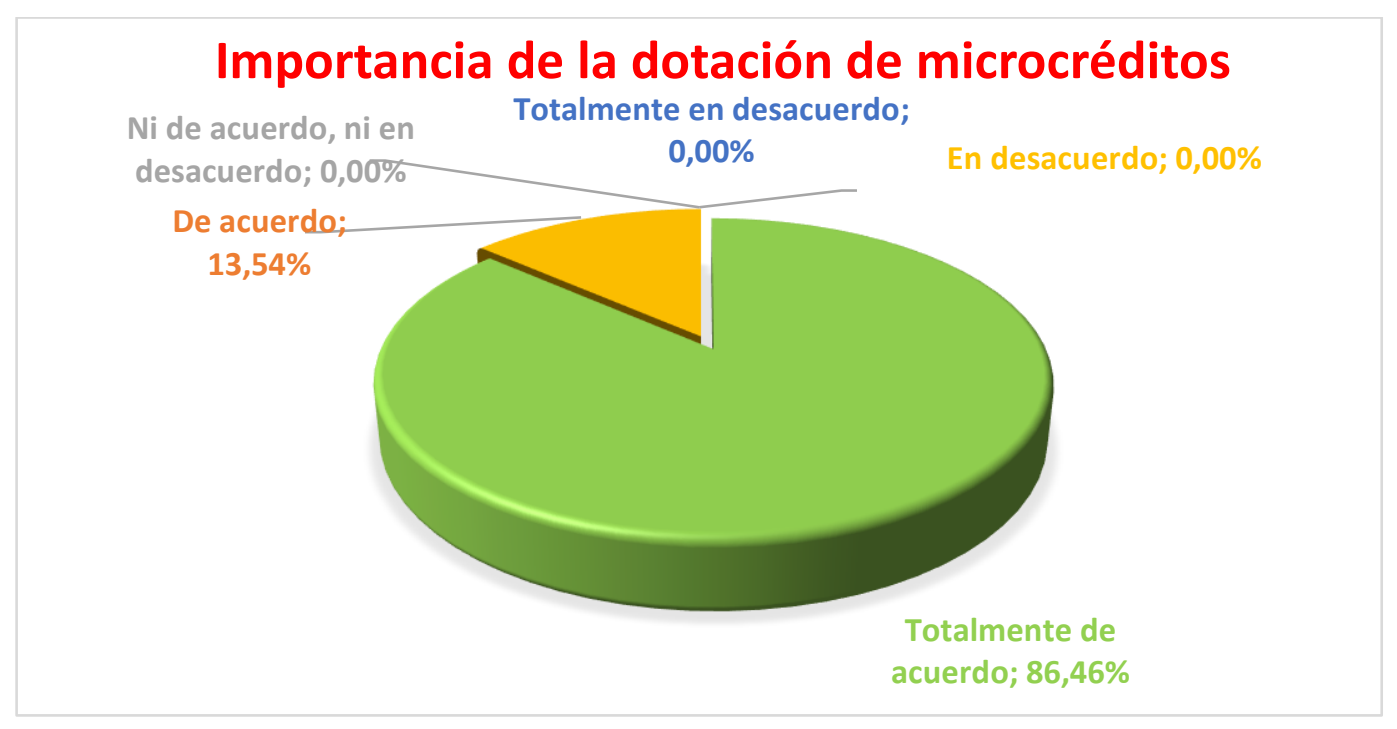

Fuente: Elaboración propia (2020).

La información recogida permitió determinar que un alto porcentaje de socios de los Bancos Comunitarios encuestados, representado por un $86,46 \%$ está totalmente de acuerdo y conformes con los microcréditos, el 13,54\% manifiestan estar de acuerdo, al unir ambas tendencias representan el 100,00\%, quienes señalan que, el microcrédito es un instrumento idóneo para mejorar las condiciones de vida de las familias y contribuir a su integración social. La promoción de los microcréditos es importante por cuanto permiten a muchas personas emprender actividades comerciales y productivas, mejorar sus ingresos y lograr una inserción activa en su medio social. La mejora de la economía familiar contribuye, suplementariamente, a resguardar la escolaridad de los hijos y a protegerlos de los peligros 
de la vida en la calle. Por otra parte, como muestran nuestro análisis, las organizaciones son en gran medida sustentables por el alto grado de cumplimiento de los prestatarios.

\section{Discusión.}

Los resultados presentados dan cuenta de que las las iniciativas de ahorro y crédito popular cumplen un papel destacado en la lucha contra la exclusión financiera, democratizando el acceso a los servicios financieros a las personas de más bajos ingresos acorde a los estudio realizados por (Ibrahim, Ahmed, \& Minai, 2018; Martínez-Carrasco, M., Eid, \& Sueiras, 2016; Sanchis Palacio \& Pascual García, 2017).

Los microcréditos constituyen un pilar para el desarrollo, el cooperativismo contribuye a la sostenibilidad social, económica y ambiental (Alianza Cooperativa Internacional (ACI) \& La Organización Internacional del Trabajo (OIT), 2015) sin embargo no deben ser concebido como una única solución para el desarrollo y la erradicación de la pobreza, por consiguiente, para que este instrumento tenga el éxito esperado, deben confluir una serie de factores que sean favorables para su gestión alcanzando altos niveles de eficiencia y especialización a decir de Gutiérrez Aguirre (2002) "tienen que ampliar su horizonte estratégico, profundizar sus procesos de eficiencia y transparencia y abrir nuevos espacios en los mercados del microcrédito (p.8).

El microcrédito debe ser una herramienta flexible y adaptada al entorno, de este modo el microcrédito es una modalidad de financiamiento que se caracteriza por prestar cantidades reducidas de capital (Marbán Flores, 2017) para impulsar micro proyectos productivos en los distintos sectores de la economía, aspecto que prevalece en iniciativas como la presentada en este estudio con características e impactos a tono con los promulgados por el Banco Grameen en Bangladesh (Yunus, 2005), Cresol en Brasil (Christopoulos \& Gonzalez, 2017), los bancos comunales patrocinados por ONGs en el Perú (Marbán Flores, 2017), entre otros

La investigación de campo realizada, así como de información secundaria obtenida da como resultado definir a 24 zonas objeto de estudio se obtuvo la siguiente información:

Tabla 1. Estado de Situación Actual de los Bancos Comunitarios al 31 de diciembre del 2019. 


\begin{tabular}{|c|c|c|c|c|c|c|c|c|c|c|c|c|c|c|}
\hline \multirow[t]{2}{*}{ № } & BANCO & CANTON & № Socios & № Socios & $\mathbf{N}^{\circ}$ & Total & Capital & AÑo & Capital & Ahorros & \multirow[t]{2}{*}{ Total } & Ingreso & Otros & Capital \\
\hline & COMUNIDAD & & Hombres & Mujeres & \begin{tabular}{|l} 
Ahorristas \\
\end{tabular} & Socios & Inicial .F.N.H & INICIO & Socios(as) & Socios(as) & & $\mathrm{X}$ Interes & Ingresos & Final \\
\hline 1 & EVANGELICOS & CAÑAR & 2 & 28 & 5 & 35 & $1.000,00$ & 2015 & 760,00 & 420,00 & $2.180,00$ & 218,51 & 41,49 & $2.440,00$ \\
\hline 2 & JUNDOCUCHO & CAÑAR & 0 & 32 & & 32 & $1.000,00$ & 2015 & 575,00 & 460,00 & $2.035,00$ & 81,36 & 14,23 & $2.130,59$ \\
\hline 3 & HIERBA BUENA & CAÑAR & 6 & 15 & & 21 & $1.000,00$ & 2015 & 525,00 & 100,00 & $1.625,00$ & 77,81 & 33,75 & $1.736,56$ \\
\hline 4 & MALAL & CAÑAR & 0 & 21 & & 21 & $1.000,00$ & 2015 & 500,00 & 148,00 & $1.648,00$ & 50,00 & 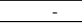 & $1.698,00$ \\
\hline 5 & ZHUYA 1 & CAÑAR & 5 & 34 & 2 & 41 & $1.000,00$ & 2015 & $4.023,37$ & 76,00 & $5.099,37$ & 470,00 & - & $5.569,37$ \\
\hline 6 & POSTA ALTA & CAÑAR & 3 & 22 & 3 & 28 & $1.000,00$ & 2015 & $1.580,00$ & 263,00 & $2.843,00$ & 349,66 & 219,15 & $3.411,81$ \\
\hline 7 & SAN JOSE DE LA POSTA & CAÑAR & o & 24 & & 24 & $1.000,00$ & 2015 & $1.240,00$ & 345,00 & $2.585,00$ & 381,69 & 18,31 & $2.985,00$ \\
\hline 8 & GAZZA & CAÑAR & 7 & 23 & & 30 & $1.000,00$ & 2015 & 500,00 & 148,00 & $1.648,00$ & 50,00 & - & $1.698,00$ \\
\hline 9 & ZHUYA 2 & CAÑAR & 2 & 26 & & 28 & $1.000,00$ & 2015 & 500,00 & 200,00 & $1.700,00$ & - & - & $1.700,00$ \\
\hline 10 & SAN JOSE & CAÑAR & 10 & 14 & & 24 & $1.000,00$ & 2015 & 500,00 & 148,00 & $1.648,00$ & 50,00 & - & $1.698,00$ \\
\hline 11 & CHONTAMARCA & CAÑAR & 4 & 37 & & 41 & $1.000,00$ & 2015 & 500,00 & 148,00 & $1.648,00$ & 50,00 & - & $1.698,00$ \\
\hline 12 & MILACRUZ & CAÑAR & 4 & 26 & & 30 & $1.000,00$ & 2015 & 500,00 & 150,00 & $1.650,00$ & 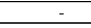 & - & $1.650,00$ \\
\hline 13 & AYANCAY & AZOGUES & 5 & 28 & 5 & 38 & $2.000,00$ & 2010 & $1.000,00$ & 300,00 & $3.300,00$ & 500,00 & - & $3.800,00$ \\
\hline 14 & M. AXULIADORA & AZOGUES & 6 & 15 & & 21 & $1.000,00$ & 2010 & 525,00 & 100,00 & $1.625,00$ & 77,81 & 33,75 & $1.736,56$ \\
\hline 15 & BAYAS & DELEG & 0 & 21 & & 21 & $1.000,00$ & 2010 & 500,00 & 148,00 & $1.648,00$ & 50,00 & - & $1.698,00$ \\
\hline 16 & SOLONO & BIBLIAN & 5 & 34 & 3 & 42 & $1.000,00$ & 2010 & $4.023,37$ & 76,00 & $5.099,37$ & 470,00 & - & $5.569,37$ \\
\hline 17 & CUYTUN & BIBLIAN & 3 & 22 & 3 & 28 & $1.000,00$ & 2010 & $1.580,00$ & 263,00 & $2.843,00$ & 349,66 & 219,15 & $3.411,81$ \\
\hline 18 & SAGEO & CAÑAR & 0 & 24 & 2 & 26 & $1.000,00$ & 2010 & $1.240,00$ & 345,00 & $2.585,00$ & 381,69 & 18,31 & $2.985,00$ \\
\hline 19 & LA POSTA BAJA & SUSCAL & 7 & 23 & & 30 & $1.000,00$ & 2012 & 500,00 & 148,00 & $1.648,00$ & 50,00 & - & $1.698,00$ \\
\hline 20 & SUSCAL & SANTA ISABEL & 2 & 26 & & 28 & $1.000,00$ & 2014 & 500,00 & 200,00 & $1.700,00$ & & - & $1.700,00$ \\
\hline 21 & SANTA TERESA & SANTA ISABEL & 10 & 14 & & 24 & $1.000,00$ & 2014 & 500,00 & 148,00 & $1.648,00$ & 50,00 & - & $1.698,00$ \\
\hline 22 & ZHAGLI & SANTA ISABEL & 4 & 37 & & 41 & $1.000,00$ & 2014 & 500,00 & 148,00 & $1.648,00$ & 50,00 & - & $1.698,00$ \\
\hline 23 & SALINAS & SANTA ISABEL & 4 & 26 & & 30 & $1.000,00$ & 2014 & 500,00 & 150,00 & $1.650,00$ & - & - & $1.650,00$ \\
\hline 24 & SANTA ISABEL & SANTA ISABEL & 5 & 28 & 5 & 38 & $2.000,00$ & 2014 & $1.000,00$ & 300,00 & $3.300,00$ & 100,00 & - & $3.400,00$ \\
\hline & TOTAL & & 94 & 600 & 28 & 722 & $26.000,00$ & & $24.071,74$ & $4.932,00$ & $55.003,74$ & $3.858,19$ & 598,14 & $59.460,07$ \\
\hline
\end{tabular}

Fuente: Elaboración propia (2020). Basado en la información de la Fundación Nuevos Horizontes (2019).

Si a la presente información se aplica el análisis costo-beneficio, mismo que es un instrumento financiero que mide la relación que existe entre los costos y beneficios asociados a una inversión, tal como la creación de una nueva empresa o el lanzamiento de un nuevo producto, con el fin de conocer su rentabilidad, en donde $\mathrm{B} / \mathrm{C}>1$ indica que los beneficios superan los costes, por consiguiente, los Bancos Comunitarios están generando beneficios.

El Análisis indicó una relación beneficio/coste de la tabla se determinó 1,11 significa que se está esperando 1,11 dólares en beneficios por cada \$ 1 en los costes. Sin embargo en la evaluación del programa es de menester establecer el beneficio social, según Espin Maldonado, Bastidas Aráuz, \& Durán Pinos, (2017) que supera con creces al beneficio financiero, según los resultados del análisis de impacto social establecidos en este estudio.

Sin embargo, la información recogida permitió determinar los sectores son débiles en cuanto a la organización para la producción y comercialización agropecuaria, por ello es fundamental identificar estrategias que potencialicen la operación y sustentabilidad de sus micro proyectos en el tiempo, de ahí que se vuelve importante trabajar en primer lugar en el fortalecimiento de la organización de los productores, con base a sus experiencias sin desconocer las formas tradicionales de cultivar el suelo y comercializar.

Los productores debidamente organizados en las parroquias no solo deben tener en cuenta la toma de decisiones, sino que con el transcurrir del tiempo y bajo las directrices del 
reglamento interno del Banco Comunal, sentar el principio de autogestión y fortalecimiento de sus organizaciones, que muy bien podría ser mediante el apoyo de migrantes residentes en Estados Unidos y Europa, en donde una buena parte de estos son oriundos de estos sectores.

Es importante señalar que en las reuniones para establecer los planes de acción y estrategias de trabajo, debe propender a optar por un mecanismo que retroalimente estos planes (Ferrándiz, Gutiérrez, \& Villasante, 2019) a través de la información y evaluación permanente de los receptores directos de los servicios de apoyo tanto en la parte de la organización, manejo de bancos comunales, otorgamiento de los microcréditos, la producción, así como la asistencia técnica y su evaluación.

\section{Conclusiones.}

Se explican las principales conclusiones, integrando los resultados de las encuestas, y la técnica de la observación:

- Como se sostiene a lo largo del estudio es necesario promover los microcréditos porque contribuyen a mejorar los ingresos y la inserción social de los sectores vulnerables.

- Es importante la formación y adiestramiento que viene proporcionando la Fundación Nuevos Horizontes, por tanto, uno de los aspectos a considerar es la capacitación integral de los beneficiarios directos de los microcréditos, por tanto, en todo proceso de préstamo, dependiendo de la actividad a emprender y en sus diferentes componentes se da una capacitación a través de la transferencia de tecnología, lo cual permite un adecuado uso del crédito y por ende asegura su recuperación.

- La capacitación debe ser dirigida a grupos de beneficiarios, que contempla la consecución de talleres y conferencias, capacitación sobre el manejo de los microcréditos y su correcta utilización, capacitación agropecuaria en temas relativos al manejo de recursos naturales, aspectos productivos, organizacionales, de comercialización, comunitarios y de género de gestión micro empresarial y plan de negocios; difusión de aspectos socio-económicos y prácticas agropecuarias; promoción y consolidación de organizaciones con enfoque de género. 
- La presencia de los 24 Bancos Comunitarios tiene como propuesta el apoyo al sector agrícola y pecuario con la dotación de microcréditos para promover en los sectores la producción y comercialización para de esta manera impulsar en estas zonas el desarrollo económico y social de los productores agropecuarios de las parroquias de las provincias del Azuay y del Cañar, mediante el uso racional de los recursos naturales y de la comercialización con productos competitivos, que garantice beneficios para los productores y consumidores, promoviendo las virtudes de organizarse en comunidad y encaminarles con una visión micro empresarial y la capacidad de autogestión para fortalecer las capacidades individuales y sociales de los productores de las zonas.

- De esta manera, emprender actividades encaminadas a crear oportunidades de empleo para obtener ingresos que permitan alcanzar un nivel de vida digno y lleno de oportunidades, para lo cual se debe tener presente un aprovechamiento y optimización de los recursos naturales, mediante un manejo adecuado y rentable que permita tener un criterio de gestión micro empresarial de calidad con productores organizados y capacitados, fortaleciendo la cultura social que aprecie los valores del medio rural y que considere los recursos naturales que posee como un medio para mejorar la calidad de subsistencia y evitar la migración de los pobladores de estas zonas hacia otros sectores de la economía o al exterior.

- Las condiciones y calidad de vida de los productores agrícolas y pecuarios de estos sectores, traerá un incremento de los ingresos, una disminución de la migración y desempleo, y por ende una reducción de las desigualdades sociales.

- La incorporación de los pobladores de las zonas a las fuentes de trabajo, otorgando los pequeños préstamos a los productores y dueños del uso del suelo. En el proceso de producción y de comercialización, al acrecentarse la actividad productiva agronómica, trae consigo fuentes de trabajo directos e indirectos. En los directos se benefician los involucrados en el proyecto esto es por una parte los productores y por otra los consumidores y con respecto a los indirectos que incluyen a actores sociales de la agroindustria, transporte y comercio. 
- Por otra parte, se debe propiciar y participar en ferias y exposiciones para hacer conocer los productos y servicios que ofrecen y poder buscar nuevos clientes tanto en la economía local, regional, nacional como en el exterior.

- Con relación a facilitar los pagos de los créditos, es importante poner a su disposición mecanismos a los que accedan los socios de los Bancos Comunales, para garantizar la recuperación de la cartera de créditos. Para tener un buen perfil crediticio y acceder a montos y plazos mayores en el futuro. El crédito es dar o recibir dinero para satisfacer necesidades, a un interés, para ser devuelto en un tiempo determinado, para el presente caso en un año o menos. Por consiguiente, se dice que la administración de la "carteras de préstamos", es efectiva cuando se otorgan buenos créditos, apoyando al crecimiento sostenido del patrimonio y la sobrevivencia en el largo plazo. Cada socio o socia tiene derecho a solicitar un crédito conforme a una necesidad específica.

- Emplear información contable y financiera como instrumentos para evaluar la situación financiera de los Bancos Comunitarios, y corregir a tiempo cualquier desorientación que se presente en el camino. Para ello es importante conocer las herramientas básicas contables y las actividades económicas y financieras en forma cronológica y cuantificada para clasificarlas, registrarlas, resumirlas en Estados Financieros y luego, entenderlos, analizarlas e interpretarlas.

- El análisis indicó, que la Autogestión de los beneficiarios de los Bancos Comunitarios a futuro, debe basarse en organizaciones debidamente consolidadas con capacidad de autogestión en los aspectos financieros, productivos de comercialización, sociales y políticos y se fundamenta en los logros del proyecto que se reflejan en una mejora de las condiciones y calidad de vida de los productores y de la población en general. Los productores organizados en los Bancos Comunales capacitados en gestión de procesos seguirán produciendo y generando una producción que permita la preservación del ambiente, económicamente rentable y socialmente sostenible.

- Así mismo, los Bancos Comunitarios, deben mantener permanentes canales de comunicación con las instituciones involucradas en este proceso y con otros proyectos similares para intercambiar experiencias y contribuir al desarrollo local, regional y nacional, replicando este modelo de gestión en otras regiones. De la misma 
manera se establecerán mecanismos de comunicación interna, a través de reuniones, charlas, informes, rendición de cuentas, talleres, entre otros, con los usuarios para mantener la unión de sus miembros y la permanencia de los mismos.

\section{Referencias bibliográficas.}

Asamblea Constituyente. (2008). Constitución de la República del Ecuador. Montecristi: Asamblea Constituyente, Gaceta oficial No 449 del 20 de octubre del 2008.

Bernal, C. (2006). Metodología de la investigación. Para administración, economía, humanidades y ciencias sociales. México: Pearson Educación.

Alianza Cooperativa Internacional (ACI), \& La Organización Internacional del Trabajo (OIT). (2015). Las cooperativas y los Objetivos de Desarrollo Sostenible. Organización Internacional Del Trabajo, 24. https://doi.org/10.1016/j.bcp.2011.07.081 [doi]

Bezboruah, K. C., \& Pillai, V. (2015). Exploring the Participation of Women in Financial Cooperatives and Credit Unions in Developing. VOLUNTAS: International Journal of Voluntary and Nonprofit Organizations, 913-940. https://doi.org/10.1007/s11266-0149467-9

Calderón Salazar, J. (2011). Microcrédito opción de desarrollo. Ecuador- Cuenca: GráficasHernádez Cía. Ltda.

Christopoulos, T. P., \& Gonzalez, L. (2017). ACHIEVING FAMILY FARMERS 'DEMANDS FOR MICROCREDIT THROUGH CREDIT UNIONS: A FRAMEWORK FOR DISCUSSION. $\quad 18(5), \quad 116-143 . \quad$ https://doi.org/10.1590/167869712017/administracao.v18n5p116-143

Espin Maldonado, W. P., Bastidas Aráuz, M. B., \& Durán Pinos, A. (2017). Propuesta metodológica de evaluación del balance social en asociaciones de economía popular y solidaria del Ecuador. CIRIEC-España, Revista de Economía Pública, Social y Cooperativa, (90). https://doi.org/10.7203/ciriec-e.90.9240

Ferrándiz, J. C., Gutiérrez, P. M., \& Villasante, T. R. (2019). Discussing participatory methodologies: A process in eight jumps. Empiria, (44), 21-45.

Fundación Nuevos Horizontes (2019), Bancos Comunitarios para lideres y promotores, Ecuador: PROCAEF, FEPP Regional Ibarra.

Grupo BID. (2011). Recuperado el 26 de Agosto de 2011, de Fondo Multilateral de Inver- 
siones: http://www5.iadb.org/mif/\#enterprise.

Gutiérrez Aguirre, I. (2002). Las microfinancieras: por la sostenibilidad y un marco legal apropiado. Encuentro, (60), 8-21. https://doi.org/10.5377/encuentro.v0i60.4136

Hernández Sampieri, R., Fernández-Collado, C., \& Baptista Lucio, P. (2016). Metodología de la Investigación (Quinta Edición). México: Panamericana Formas e Impresos S.A.pá51.

Hurtado de Barrera, J. (2010). Guía para la comprensión holística de la ciencia, Tercera Edición, Fundación Sypal: Caracas-Venzuela.

Ibrahim, Y., Ahmed, I., \& Minai, M. S. (2018). The influence of institutional characteristics on financial performance of microfinance institutions in the OIC countries. Economics and Sociology. https://doi.org/10.14254/2071-789X.2018/11-2/2

Jordán, F., \& Román, j. (2004). La situación, tendencias y posibilidades de las microfinanzas. Quito: Abya Yala.

Marbán Flores, R. (2017). Las ong microfinancieras peruanas: siguen manteniendo su misión social? REVESCO Revista de Estudios Cooperativos, 123, 114-142. https://doi.org/10.5209/REVE.52987

Martínez-Carrasco, F., M., M. A., Eid, M., \& Sueiras, J. C. (2016). Inclusión financiera en el ámbito rural mediante cajas de ahorro. Estudio de una experiencia en México. Perfiles Latinoamericanos, 24(48), 185-211. https://doi.org/10.18504/pl2448-0082016

Sanchis Palacio, J. R., \& Pascual García, E. (2017). Ethic bank and cooperative bank. A comparative analysis through the study of Caixa Popular and Ethical Banking Fiare. REVESCO Revista de Estudios Cooperativos, 124(124), 152-174. https://doi.org/10.5209/REVE.54921

Torres, L. (2000). El crédito microempresarial en el Ecuador. Quito: Fundación Avatar.

Yunus, M. (2005). Microcredit changes lives . Appropriate Technology, 32(1), 6-8. Retrieved from http://proquest.umi.com.ezproxy.library.uq.edu.au/pqdlink?Ver=1\&Exp=10-15$2015 \& \mathrm{FMT}=7 \& \mathrm{DID}=846350451 \& \mathrm{RQT}=309$

Yunus, M. (2006). El Banquero de los Pobres. Los microcréditos y la batalla contra la pobreza en el mundo. Barcelona: PAIDÓS. 


\section{PARA CITAR EL ARTÍCULO INDEXADO.}

Becerra Molina, E., \& Cuadrado Sánchez, G. (2020). El microcrédito productivo como dinamizador de la economía campesina en la región del Austro. Visionario Digital, 4(4), 631. https://doi.org/10.33262/visionariodigital.v4i4.1416

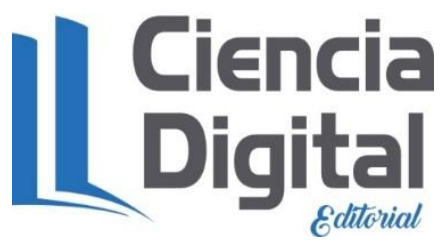

El artículo que se publica es de exclusiva responsabilidad de los autores y no necesariamente reflejan el pensamiento de la Revista Visionario Digital.

El artículo queda en propiedad de la revista y, por tanto, su publicación parcial y/o total en otro medio tiene que ser autorizado por el director de la Revista Visionario Digital.
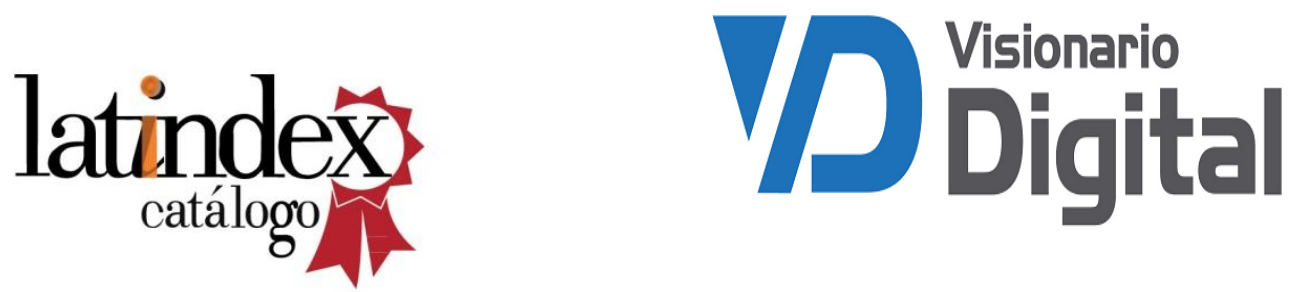